\title{
Research on the Dual Tutorial System Guidance Mode in Graduation Thesis of Application-oriented Undergraduate E-Commerce Specialty
}

\author{
Yi-lei PEI ${ }^{1, a}$, Wan-xin XUE ${ }^{2, b,{ }^{*}}$ and Dan-dan $\mathrm{LI}^{3, \mathrm{c}}$ \\ ${ }^{1,2,3}$ Management College, Beijing Union University, Beijing, China \\ axuewanxin@126.com, ppeiyilei@126.com, clidandanhdj@163.com
}

Keywords: Graduation Thesis, Dual Tutorial System, E-Commerce Specialty, Applied-oriented Undergraduate.

\begin{abstract}
With the needs of application-oriented undergraduate E-Commerce specialty construction and development, the role of the practice teaching link for graduation thesis is becoming more and more obvious. According to the talent cultivation goal of application-oriented undergraduate E-Commerce specialty, this paper constructs the "Dual Tutorial System" guidance mode, analyzes all aspects of the module, and discusses the value of the implementation.
\end{abstract}

\section{Introduction}

Application-oriented undergraduate E-Commerce specialty combines with social reality closely, its application is very strong, needs to integrate with enterprises, in order to enhance students' ability to analyze and solve practical problems. The dual tutorial system discussed in this paper meets the needs of this area, cultivates students' ability to put the theory into the practice, and meets the needs of the employing units better.

\section{The Definition of "Dual Tutorial System" in the Graduation Thesis of Application-oriented Undergraduate E-Commerce Specialty}

Dual tutorial system was born in early 1990s. First it refers to the way to cultivate talents jointly using in-school and out-school tutors in graduate education [1]. The purpose is to improve students' ability to combine the theory with the practice, and to cultivate more practical talents for the society [2]. Under the socialist market economic system reform, the "independent choice, two-way choice" has become a reality [3]. Dual tutorial system is produced under the background of this reform. The dual tutorial system guidance mode in graduation thesis of application-oriented undergraduate E-commerce specialty this paper discusses is a kind of flexible cultivation mode for teaching students in accordance with their aptitude, according to the training objectives and characteristics of E-commerce specialty, combined with the characteristics of students of E-commerce specialty. Through the joint guidance from professional tutors in school and enterprise tutors out school from Internet industry, two tutors explore and decide together the link of topic selection, theory link, practice link, integration link, defense link for graduation thesis. In general, tutors in school focus on guiding students' academic aspects; while tutors out school emphasize training students' practical ability and the ability to treat people and things. 


\section{The Problems in Graduation Thesis of Application-oriented Undergraduate E-commerce Specialty}

\section{The Improper Awareness and Attitude}

First of all, many students do not know the place. According to research group survey, more than half of students believe that graduation thesis or graduation design does not need the practical investigation and they can write it out for the last month. Secondly, most of students hold the unserious attitude of graduation thesis or graduation design, and do not pay attention to it. Students despise the graduation thesis psychologically, think that they just make a show for the thesis or design, and may pass it finally. The negative information seniors pass also deepens the indifference psychology.

\section{The Old Topic Selection and Lack of Quantitative Analysis}

E-commerce specialty has very close contact with the practice, so students complete the graduation thesis or design topics according to the actual problem or the phenomenon of enterprises. But when students determine topics, they often choose the topics that previous graduates have done. Topics are obsolete, with no innovation; some design topics are only determined depending on students' interests, and are all virtual topics, without relying on actual enterprises. At the same time, students' foundation in E-commerce specialty in statistics analysis is weak, although they have learned training courses of "Statistics" and "data analysis". When students conduct simple investigation analysis in the thesis, they only use simple models and analysis software, or they analyze two unimportant variables in the paper, in order to use the analysis tool.

\section{Emphasizing the Theory and Ignoring the Practice in Writing Mode of Graduation Thesis}

In the past, the graduation thesis of E-commerce major is too heavy theory, light practice, emphasizing the complete theoretical analysis of the system and the uniform format of the strict standard. Some students have not developed a good habit of thinking, with the poor theoretical basis, and have the weak ability to search the literature information; the paper is also difficult to do a good job. Therefore, it is not realistic to expect them to write the paper with higher theoretical depth and practical significance. Normative aspects of the paper are also difficult to do.

\section{The Construction of "Dural Tutorial System" in Graduation Thesis of the Application-oriented Undergraduate E-Commerce Specialty}

\section{Building Module}

Tutor selection. E-Commerce specialty invites Internet industry experts, E-Commerce Association experts, E-Commerce enterprise experts as enterprise tutors which have the background of Internet industry and E-Commerce enterprise operation, and compose the powerful enterprises tutor group.

Paper/Design Topic Selection. This is the first link to do a good job of graduation thesis. Strict requirement on the topic selection is the premise to ensure the quality of graduation thesis. According to the talent cultivation goal of application-oriented undergraduate E-Commerce specialty, enterprise tutors out school begin to involve from graduation thesis/design topic selection, put forward some actual problems and actual demands E-Commerce enterprises have encountered in the operation and 
management, then students select topics which meet students' interest characteristics and enhance their practical ability under the guidance of tutors in school. Thus such topics are not separated from social practice, and also have the certain theoretical value, which can reflect the application-oriented talent cultivation goal in college.

Practice exercise. In the second half of the seventh semester, students enter the enterprise practice formally in the semester. Enterprise tutors out school, according to the actual requirements of enterprises, provide students with targeted internship positions, or guide students to choose suitable positions, to carry out practical activities for half a semester. During the practical training period, enterprise tutors out school supervise and guide students' practical activities, cultivate their good professional habits, and improve their practical abilities. At the same time, professional tutors in school also need to communicate with enterprise tutors out school in time and help to improve students' abilities to integrate theory with practice.

Thesis/Design Finalization. Students go back to school and summarize the knowledge learned in practice process, and integrate the work at the first two stages in enterprises, at the end of the internship, under the guidance of enterprise tutor, complete interviews, questionnaires, distribution and data recovery of graduation thesis/design or improve graduation design function and column, and then complete the final thesis/design. Students need to combine the advice of enterprise tutors out school and professional tutors in school, dock the professional knowledge during the university and practical experience in the enterprise, and think and summarize the whole thesis/design.

Thesis Oral Defense. At the beginning of May each year, E-Commerce specialty organizes all students to carry out the defense unifiedly, and use the joint defense team which is composed of professional tutors in school and enterprise tutors out school. Graduation thesis/design mark assessment is not only according to the reference thesis/design quality and defense performance, but also attendance statistics and actual performance report that enterprise tutor out school provides, and conducted by the double tutors together. The construction mode of "Dual Tutorial System" in the graduation thesis of application-oriented undergraduate E-Commerce specialty is as shown below:

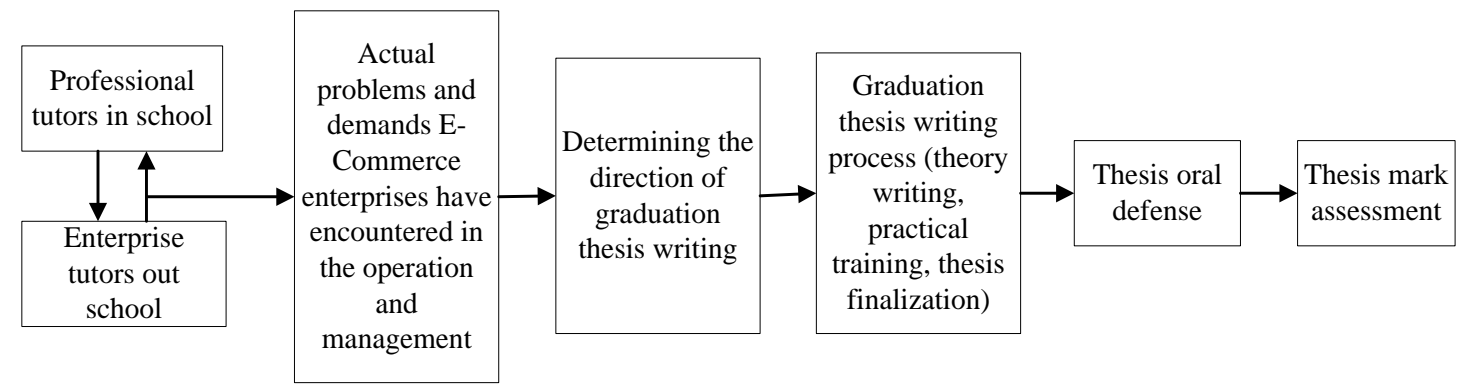

Figure 1. The construction mode of "Dual Tutorial System" in the graduation thesis of application-oriented undergraduate E-Commerce specialty

\section{Value}

The graduation thesis/design is guided by the dual mentor jointly, which has a certain positive significance in a certain extent, whether from the perspectives of students, enterprises, or schools and teachers.

From the perspectives of students, students complete graduation thesis in the enterprise, which can enhance students' comprehensive ability including professional level and practical ability significantly. Students can understand the enterprise as soon as possible, improve the practibility of its theoretical knowledge, at the same time, 
enhance students' communication skills, anti-frustration ability, and lay the foundation for adapting to society as soon as possible.

From the perspectives of enterprises, enterprise tutors out school and professional tutors in school guide the graduation thesis/design together, which can reduce enterprise cost and increase the understanding of the future staff.

From the perspectives of schools and teachers, it is conducive to ease the contradiction of the shortage of teaching resources, accelerate the pace of industrialization of scientific and technological achievements.

\section{Acknowledgement}

This research was financially supported by the Project of Construction of Talents' Cultivation Quality: The Construction of Professional Groups in Beijing Universities (PXM2016_014209_000001) and the Project of Education and Teaching Research and Reform of Beijing Union University in 2016 (JJ2016Q047).

\section{References}

[1] Sun Yuxia, Zhou Haiyan, Li Xiaoxia, Double tutor of undergraduate graduation theses at medical university, Basic Medical Education, 2014, 16(30): 247-249.

[2] Zhao Yu, Research on the Double Tutorial System of graduation thesis of financial management major, Contemporary Education Research and Teaching Practice, 2016, (2): 268.

[3] Ge Zhicai, Li Li, Research on the "Dual Tutorial System" guiding mode of economics and management thesis at Independent College, Forward Position, 2013, (23): 133-134. 